Arqueologia Pública

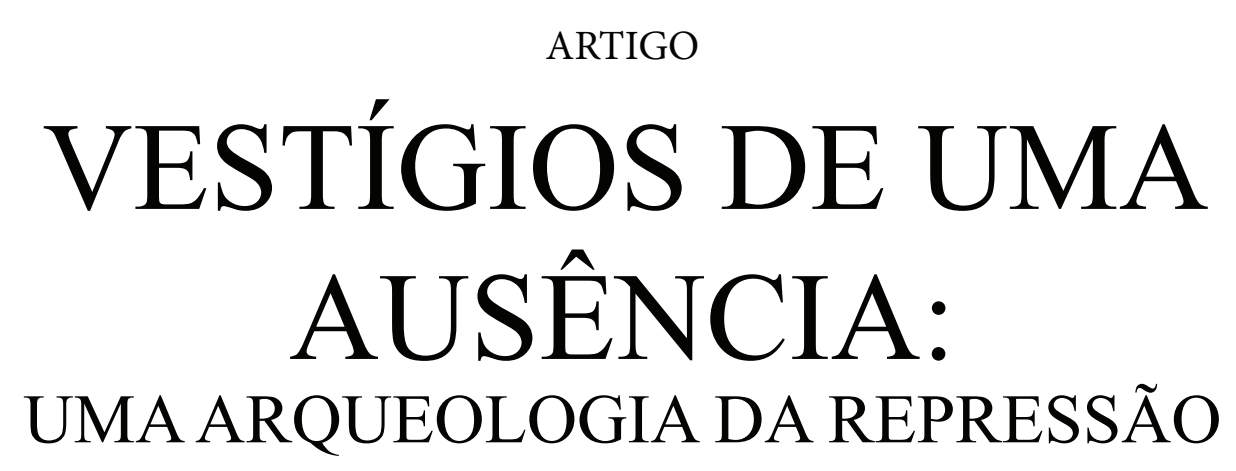

Beatriz Valladão Thiesen

Célia Maria Pereira

Eduarda Rippel

Gabriel Rodrigues Vespasiano

Ingrend Guimarães Cornaquini

Júlio Toledo

Mariana Fernandez 


\title{
ARTIGO
}

\section{VESTÍGIOS DE UMA AUSÊNCIA: UMA ARQUEOLOGIA DA REPRESSÃO}

\author{
Beatriz Valladão Thiesen ${ }^{1}$ \\ Célia Maria Pereira ${ }^{2}$ \\ Eduarda Rippel ${ }^{3}$ \\ Gabriel Rodrigues Vespasiano ${ }^{4}$ \\ Ingrend Guimarães Cornaquini ${ }^{5}$ \\ Júlio Toledo ${ }^{6}$ \\ Mariana Fernandez ${ }^{7}$
}

"É para os desesperados que nos foi dada a esperança"

Walter Benjamin ${ }^{8}$

\section{RESUMO}

Relatamos aqui uma experiência de Arqueologia Pública realizada com o tema dos desaparecidos da Ditadura Militar brasileira. O trabalho objetivou atingir as subjetividades e provocar um sentido de pertencimento. Para tanto, utilizando os caminhos da memória e dos afetos, empregando a cultura material e o abandono do texto escrito. Pela utilização de um simulacro, propusemos fazer uma tradução dos desaparecimentos ocorridos durante o período da ditadura.

1 Professora Associada do Curso de Bacharelado em Arqueologia da Universidade Federal do Rio Grande-FURG. Contato: beatrizthiesen@yahoo.com.br

2 Arte Educadora e Bacharelanda do Curso de Bacharelado em Arqueologia da Universidade Federal do Rio Grande - FURG

3 Bacharelando do Curso de Bacharelado em Arqueologia da Universidade Federal do Rio Grande - FURG

4 Bacharelando do Curso de Bacharelado em Arqueologia da Universidade Federal do Rio Grande - FURG

5 Bacharelando do Curso de Bacharelado em Arqueologia da Universidade Federal do Rio Grande - FURG

6 Bacharelando do Curso de Bacharelado em Arqueologia da Universidade Federal do Rio Grande - FURG

7 Bacharelando do Curso de Bacharelado em Arqueologia da Universidade Federal do Rio Grande - FURG

8 BENJAMIN, Walter. Les affinitésélectivesde Goethe, in Walter Benjamin. Oeuvres Choisies. Trad. Maurice de Gandillac. Paris, Julliard, 1959. 
Palavras-chave: Ditadura Militar; Cultura Material; Arqueologia da Repressão.

\begin{abstract}
This article was constituted upon our experiences within public archaeology, based on the theme: politic missing persons from brazilian Military Dictatorship. Our research has its goals on reaching the subjectivities and to induce a sense of belonging, evoking memories and attachment through material culture only, putting aside made discourses such as written texts. We describe in this article how our simulacrum installation was used to translate the disappearances during the dictatorship period.
\end{abstract}

Keywords: Military Dictatorship; Material Culture; Archaeology of Repression.

\title{
RESUMEN
}

Relatamos aquí una experiencia de Arqueología Pública realizada con el tema de los desaparecidos de la Dictadura Militar brasileña. El trabajo objetivó atingir las subjetividades y provocar un sentido de pertenencia. Para tanto, utilizamos los caminos de la memoria y de los afectos, empleando la cultura material y abandonando el texto escrito. Por la utilización de un simulacro, propusimos hacer una traducción de los desaparecimientos ocurridos durante el período de la dictadura.

Palabras clave: Dictadura Militar; Cultura Material; Arqueología de la Represión.

\section{CINQUENTA ANOS SE PASSARAM E AS FERIDAS CONTINUAM ABER-} TAS

O golpe de 1964 me encontrou ainda criança e eu cresci naqueles dias tempestuosos, entre o medo e a ignorância, entre o espanto e a ingenuidade. Em 1968, ouvi os Beatles pela primeira vez. E gostei. Tinha, então, 10 anos. A Jovem Guarda não me empolgava, mas achava Ronnie Von um príncipe. Odiava as freiras do colégio, o uniforme que nos assexualizava, e sonhava em ir (escondida) à loja - frequentada pela juventude rica e supostamente rebelde porto-alegrense - que vendia uniformes americanos usados por soldados na guerra do Vietnã.

Não ouvi falar no AI-5. Minha pré-adolescência misturou a euforia da chegada do homem à lua e a vitória do Brasil na copa de 1970, com um desconforto, algo que eu 


\section{VESTÍGIOS DE UMAAUSÊNCIA}

não entendia, mas que ficava no ar quando adultos conversavam e mencionavam coisas sobre comunistas e generais. Havia bandidos e havia mocinhos. Não entendia bem, mas sabia que havia o bem, de um lado, e o mal, de outro.

$\mathrm{Na}$ minha casa havia muitos livros. Ouvia-se música clássica a alto volume, diariamente. Havia um clima, até certo ponto, intelectual. Meu pai me ensinava sobre Beethoven, Michelangelo e Machado de Assis. Para mim, meu pai sabia tudo. Não entendia como ele não era presidente da república: era óbvio que consertaria o país. Um dia, o vi pegar nossas apostilas da aula de religião e jogar tudo no chão bradando: "As gurias vão sair desse colégio! Essas freiras são umas comunistas!".

Ora viva! As freiras malvadas, que nos colocavam de castigo, que nos chamavam de pecadoras, que nos obrigavam a usar saias medonhas e nos condenavam a passar frio durante o inverno - já que calça comprida era proibida no colégio -, eram as comunistas. Tudo resolvido! Concordei com meu pai: "Sim, os comunistas são muito maus. Sairemos do colégio!”.

Fomos estudar em um lugar que não exigia uniforme. Podíamos matar aula (desde que não excedesse o número admitido de faltas), podíamos fumar no recreio, namorar. O paraíso. O lugar dos bons, por certo! Eu entrava, então, na adolescência. Conheci as drogas, as viagens de carona, os primeiros amores. Comecei a ver que além de Beethoven, Michelangelo e Machado de Assis, existiam muitas coisas mais. Aprendi o que era o AI-5 e o que é ter medo da polícia. Mas ainda não tinha perdido aquela doce inocência e, mesmo rindo muito com os colegas, todos abraçados e pulando juntos para trás e cantando "Este é um país que vai para frente", ainda achava que o milagre econômico dos generais tinha nos salvado: havíamos construído uma casa e não via mais meu pai, de madrugada, desesperado e contando moedinhas.

Quando entrei na Universidade, a coisa toda mudou. Ainda ingênua, conheci Marx, Engels e os anarquistas. Fiquei extasiada! Amor livre, cerveja, passeatas, discursos inflamados, e, pronto: mudamos o mundo. Apanhamos da polícia, gritamos, fomos parar nas delegacias. Sabíamos que tinha gente desaparecida. De novo, gritamos e apanhamos. Radicalizamos: deitamos em frente aos ônibus, tiramos a roupa e dançamos nus sobre a bandeira nacional. Apanhamos novamente. E gritando e apanhando, num belo dia, a ditadura acabou. O irmão do Henfil voltou, mas teve gente que nunca mais apareceu. Novamente, entre a euforia e a ignorância, esperei que tudo se resolvesse: a democracia trataria da justiça. Mas não...

Cinquenta anos se passaram e eu pensei que precisava fazer alguma coisa. Professora de Arqueologia do Mundo Contemporâneo, desafiei os meus alunos: ainda precisa- 
mos mudar o mundo. Eles responderam com a garra da juventude: "vambora"!?"

\section{A SAUDADE É O PIOR TORMENTO É PIOR DO QUE O ESQUECIMEN- TO'}

Decidimos espalhar informações, falar com a voz da arqueologia para aqueles que tivessem vivido os anos de chumbo, sem saber o que realmente acontecia. Além disso, as novas gerações, certamente, pouco ou nada sabiam sobre tudo que se passara naqueles tempos.

$\mathrm{Na}$ cidade onde vivemos, falas simples e concisas do tipo "foi um período muito bom para a economia do país", ou ainda "a polícia levava presos os marginais, e os drogados", ou, até mesmo, "não me lembro de muito, mas era uma boa vida que levávamos", dão a medida do que se conhece sobre aqueles anos. Ou do que se deseja lembrar daqueles anos. Mais do que isso, Rio Grande, único porto marítimo do estado do Rio Grande do Sul, é uma cidade que se considera devedora de um dos principais mentores da Ditadura Militar: o general Golbery do Couto e Silva ${ }^{11}$. Para grande parte da população local, o general - visto como herói -, através de sua influência no regime militar, alavancou o crescimento da cidade através de importantes obras.

A instalação Vestígios de uma ausência: uma arqueologia da repressão veio de encontro a esta percepção local, ainda muito evidente em nossos atos cotidianos. Esta instalação foi pensada pelos alunos da turma 2011 do bacharelado em Arqueologia

9 Depoimento de Beatriz ValladãoThiesen.

10 Os subtítulos deste artigo são versos de Chico Buarque de Holanda da canção "Pedaço de Mim".

11 Golbery teve uma formação militar, tendo estudado na War School de Fort Leanvenworth, no Kansas. Trabalhou no front italiano da guerra como oficial de inteligência e informações. Seu histórico de ações contra o governo começa em 1954, quando, ao lado de coronéis, redigiu uma manifesto contra o aumento do salário mínimo proposto por Getúlio Vargas. Em 1955, tentou impedir a posse de Juscelino Kubitscheck e, em 1961, tentou vetar a posse de João Goulart. Em 1962, criou e dirigiu o IPES (Instituto de Pesquisas e Estudos Sociais) que passou a grampear ilegalmente milhares de telefones no Rio de Janeiro, reunindo arquivos e dossiês que mais tarde serviram para criar o SNI (Sistema Nacional de Informações) em 1964, - quando participou ativamente do golpe militar - com intuito de espionar e perseguir qualquer um que estivesse tentando conspirar contra o regime. Criou uma máquina responsável por centenas de desaparecimentos, mortes e torturas. Por ser natural de Rio Grande e por ter realizado ações como a criação da atual Universidade Federal do Rio Grande e a transferência do $5^{\circ}$ Distrito Naval de Florianópolis para Rio Grande, é considerado por muitos como um benfeitor local. Essa imagem reflete-se em recorrentes homenagens feitas pela prefeitura local e por outras instituições. Recentemente, em 2008, o $6^{\circ}$ Grupo de Artilharia e Campanha (GAC) inaugurou um monumento a Golbery intitulado $O$ reconhecimento de sua terra natal. A última reverência à memória do general diz respeito à instituição do Ano Acadêmico Golbery do Couto e Silva pela Academia Rio-grandina de Letras. 


\section{VESTÍGIOS DE UMA AUSÊNCIA}

da Universidade Federal do Rio Grande/FURG, em resposta à proposta da Professora Beatriz Thiesen, referente à disciplina de Arqueologia do Capitalismo III. A intenção do trabalho foi abordar a Ditadura Militar no Brasil através de objetos e sensações. Usando as ideias do arqueólogo Gonzalez Ruibal (2008), pretendemos demonstrar que uma arqueologia do passado recente, além de oferecer meios para contestar as versões oficiais dos fatos, também é capaz de escancarar o que nos causa ódio e repugnância. Ressaltese que ela foi a única intervenção trazendo à tona o tema da Ditadura Militar realizada na cidade do Rio Grande em abril de 2014, mês que marcou os cinquenta anos do golpe.

Resolvemos revelar, não através das palavras, mas da cultura material ${ }^{12}$, os rostos das vítimas da ditadura, mostrando tanto o visível, como as realidades ocultas da história: a ausência. Quisemos, seguindo Potter (1994), provocar a autorreflexão e integrar teoria e prática. Concordamos com Connerton (2009) que o esquecimento é uma característica da modernidade e que precisamos realizar esforços para documentar a vida contemporânea para a sociedade futura. Foi assim que, com um texto de Alfredo Ruibal (2008), nas mãos e mil ideias na cabeça ${ }^{13}$, nasceu o Vestígios de uma ausência: uma arqueologia da repressão.

$\mathrm{O}$ autor de Time to destroy. An archaeology of supermodernity, nos diz ${ }^{14}$ :

We need alternative ways of translating the remains from the past (Shanks 2004; Witmore $2004 a$ ), and this need is especially urgent because, given the overabundance of historical information, there is a risk of saturating memory with a proliferation of narratives and details, which may eventually neutralize and trivialize the past, and because the evidence is often very particular in its abject detail and its traumatic political implications. (RUIBAL, 2008: 250).

Assim, buscamos realizar o trabalho tomando os caminhos da memória e do afeto.

12 A tentativa que realizamos neste artigo é a de relatar, com palavras, o que realizamos, evitando o uso delas e utilizando a cultura material. Uma tarefa paradoxal, com certeza.

13 Fazemos referência aqui à célebre frase de Glauber Rocha «uma câmera na mão e uma ideia na cabeça", utilizada para se referir à produção de filmes baratos e voltados à realidade brasileira, adotando uma linguagem adequada à situação social da época e buscando a transformação social.

14 Os textos em língua estrangeira foram traduzidos livremente aqui. A responsabilidade pela tradução é nossa. "Precisamos de formas alternativas de traduzir os restos do passado (SHANKS, 2004; WITMORE, 2004) e essa necessidade é especialmente urgente no contexto do passado contemporâneo, pelo menos, por duas razões: porque, dada a superabundância de informações históricas do passado recente, há um risco de saturar a memória por uma proliferação de narrativas e detalhes, que podem eventualmente, neutralizar e banalizar o passado [...], e porque a evidênciana arqueologia da supermodernidadeé frequentemente muito especial no seu detalhe abjeto e nas suas implicações políticas traumáticas". (RUIBAL, 2008: 250).

236 Revista de Arqueologia Pública, No. 10, pp. 232-250, Dezembro de 2014 
Se, como já se disse, somos o que a nossa memória nos diz que somos, precisamos não esquecer. Porque se esquecemos, morremos em uma parte. Claro que também sabemos que a memória está permanentemente construindo-se e reconstruindo-se e, assim, é um engano pensar que podemos resgatar memórias, pois não se trata de um pacote de informações acabado (MENEZES, 1992). Ligada ao esquecimento, ela só permite lembrar de partes do passado. O que queríamos lembrar, então?

Consideramos que a arqueologia é uma atividade inerentemente política e que ela pode e deve contribuir com um mundo mais justo e humano (McGUIRRE, 2008; LITTLE \& SHACKEL, 2014). Quisemos gritar, em alto e bom som, que a história está construída por tiranias, resistências, sonhos, lutas, vaidades. Que a história não é feita apenas de heróis reconhecidos, mas também de pessoas comuns, cuja agência é ignorada, e de outras tantas pessoas banais, que tiveram que viver suas vidas com as consequências da violência, com partes que lhes foram arrancadas, com ausências... Quisemos mostrar as sombras dos rostos daqueles que estão excluídos das histórias oficiais e dos quais não devemos esquecer.

Mas memória não é só lembrança e esquecimento. Ela está em documentos, em monumentos, em museus, mas também “encontra-se nos corpos, nas experiências e nos afetos" (SILVA, 2008: 62). Ainda conforme Silva,

\begin{abstract}
Nesse sentido, podemos pensar nos afetos como formas de conhecimento, compreensão e experimentação do mundo, bem como de tradução das nossas vivências para os outros. O indivíduo está mergulhado em uma totalidade de significados, daí que não é possível pensá-lo fora dos contextos sociais. O homem está sempre, de algum modo, "afetado" e essas afeç̧ões qualificam suas "disposições para...", suas relações com o espaço e o tempo, nas suas interdependências, definindo, inclusive, porque se sente dada emoção e não outra, em situações específicas. Razão e emoção são um duplo reversível: a racionalização opera com base na afetividade em dada situação ao mesmo tempo em que utiliza seu potencial reflexivo para orientar as emoções (ibidem: 68).
\end{abstract}

Assim, consideramos a necessidade de utilizar um recurso que nos permitisse atingir as subjetividades. Pretendemos que, ao alcançar as afetividades, provocássemos um sentido de pertencimento às memórias que reconstruíamos ali. Que, através de emoções provocadas, o indivíduo vivenciasse a experiência proposta e pudesse, assim, se considerar como parte de uma história da qual ele também é personagem.

Através de um simulacro ${ }^{15}$ (BAUDRILLARD, 1991), propusemos fazer uma tradu-

15 Utilizamos simulacro no sentido de Jean Baudrillard (1991), ainda que para este autor, um simulacro seja um signo sem vínculos com o real, que se apresenta mais real que a realidade. Para este autor, o simulacro não mantém qualquer relação com qualquer realidade. Para nós, a construção desse simulacro obedeceu critérios de realidade. Ainda assim, tomamos de Baudrillard a ideia defendida em Simulacros e Simulação de que na pós-modernidade os símbolos têm mais importância e mais eficácia do que a própria 


\section{VESTÍGIOS DE UMAAUSÊNCIA}

ção, ou uma metáfora, dos desaparecimentos ocorridos durante o período da ditadura. Era importante que evitássemos o uso de textos e que pudéssemos apresentar o tema de forma que "fosse capaz de nos assombrar" (SHANKS apud RUIBAL, 2008: 251).

Hélio Oiticica - artista experimental ${ }^{16}$ - em suas obras fazia uso de objetos e materiais que possibilitassem ao visitante explorar cores, cheiros e sons como ativadores de sentidos. A participação era o fator mais importante em sua obra. Andar descalço sobre areia, água ou pedra. Sua proposta era recuperar sentimentos, propiciar sensações. Com Vestígios..., algo semelhante ocorre, mesmo sem a intenção de obra de arte. O visitante ouve, sente cheiros, percebe cores - preto, branco, vermelho - que em alguns momentos estão presentes juntas, em outros, isoladas, como na sala escura, onde sons simultâneos ocorrem (polifonia). As cores, os sons, as imagens e os trajetos conduzem a percepções e a sensações, nos levando há um tempo que - mesmo não vivido -, através do simulacro, experimentamos. A instalação cria uma narrativa, articulando fatos ocorridos durante o regime ditatorial brasileiro, que resultou entre tantos sofrimentos, no desaparecimento de pessoas que a ele se opuseram. E nesses acontecidos, "personagens, objetos e lugares [atribuem] uma lógica sequencial e rítmica para compartilhá-lo com outras pessoas" (GLOSSÁRIO ..., 2010: 11).

A instalação age como um dispositivo - assim como em obras de arte contemporânea a partir dos anos $1960^{17}$ - solicitando a participação do espectador. Essa participação é ativada pela interação do que compõe o trabalho e as memórias, vivências,

realidade e que simulacros, como simulações imperfeitas do real, fascinam o espectador muito mais que o próprio objeto reproduzido.

16 Helio Oiticica foi um dos primeiros artistas a usar o espaço e todos os sentidos humanos em seu trabalho. Na proposta que apresentamos aqui, Oiticica é inspirador. Como ele, queremos fazer ver coisas de uma forma diferente.

17 "A década de 1960 é marcada pela velocidade das vanguardas artísticas, que tem Nova Yorque como capital cultural do século XX. Dentre as manifestações artísticas como Minimalismo, Op Arte, Arte Cinética, Novo Realismo e Tropicália, a Pop Arte surgida na Inglaterra, mas apropriada e difundida pelos norte-americanos foi a vanguarda mais decisiva da década. Sem programa preestabelecido, sem manifesto, utilizando-se do repertório do cotidiano do consumo e da cultura de massa, foi rapidamente transformada em tendência internacional. Isso mostrou o poder cultural dos americanos.O desafio aos policias e os protestos dos estudantes nas ruas de Paris foi um marco que desencadeou movimentos de contestação, em vários Países, revoltas e guerrilhas urbanas. Estudantes, artistas e intelectuais ocupam as ruas, fazem passeatas. A contra cultura, a revolução cultural. Os artistas plásticos abandonam os museus, as galerias, saem da solidão dos ateliês e se misturam na multidão. É a poética do gesto, da ação, da coletividade, a utopia da arte / vida como participação do espectador na realização da obra de arte. No Brasil a Tropicália de Hélio Oiticica, foi uma das manifestações mais polêmicas, ao lado de Terra em Transe filme experimental barroco de Glauber Rocha e a peça O Rei da Vela de Oswald de Andrade, dirigida por José Celso Martinez." (http://josekuller.wordpress.com/2008/07/17/as-artes-plasticasna-decada-de-60-e-em-maio-de-68/) 
conhecimentos e subjetividades. Pode-se pensar o trabalho como a criação de um território, de um espaço, no qual cada um percorre em um ritmo particular, conduzido pela maneira como se afeta, como interage. Pode-se perceber que nesse trajeto, os estímulos geram pausas e reflexões, provocadas pela capacidade de sentir e de inserção de cada um.

Outro aspecto a enfatizar refere-se à preocupação estética que permeou todo o desenvolvimento do trabalho coletivo, desde a proposta.

É fundamental trazermos o significado da palavra estetizar: "lidar com determinado fato, acontecimento ou elemento intensificando seu valor estético, sua beleza ${ }^{18}$ e sua atratividade. Leituras e práticas estetizantes envolvem a possibilidade de sedução ou repulsa" (GLOSSÁRIO ..., 2010: 9).

Houve duas instalações, que apesar de serem em lugares bem diferentes, com públicos diferentes, mantiveram o projeto estrutural inicial intacto. A primeira foi no Prédio do Diretório Central de Estudantes da Universidade Federal do Rio Grande, com o público esperado de acadêmicos e pessoas envolvidas no âmbito universitário. A escolha, neste momento, esteve relacionada ao fato de que o prédio do DCE é um local de livre acesso aos estudantes, próximo ao Restaurante Universitário e, portanto, localizado em posição central e estratégica. A segunda instalação abrangeu um projeto bem maior, o qual se chamou Circuito Resistência Manifesta. Este projeto foi o desdobramento da proposta inicial. Neste circuito, tivemos atividades tanto na Prefeitura Municipal, no centro da cidade, quanto no Bairro Cassino, o bairro/balneário da cidade. A intenção de utilizar estes locais deveu-se à possibilidade de atingir um público amplo e diversificado. A Prefeitura, localizada na área central da cidade, favoreceria o acesso do cidadão comum, que transita cotidianamente por aquela área. O Cassino, situado a cerca de 20 quilômetros do centro, apresentava a possibilidade de atender os moradores do bairro e os turistas que frequentam o balneário. Na prefeitura, ficou a Instalação aberta ao público, e também foram feitas algumas Rodas de Conversas com convidados que trabalham diretamente com o tema da repressão, como foi o caso do Arqueólogo Andrés Zarankin, do Historiador Renato Della Vechiae, Eliane de Oliveira Rubim, integrante do Instituto Mário Alves ${ }^{19}$. Também pessoas que vivenciaram a questão na cidade,

18 Entendendo-se beleza como relação entre o objeto e o observador. Uma forma das pessoas se relacionarem entre si e com o mundo. Tudo no mundo recebe uma denominação e um valor como reflexo do sentir e do pensar, que, por sua vez, concretizam-se através de símbolos, e a partir destes, conseguimos dar significações para as nossas experiências (DUARTE JR, JoãoFrancisco. "O que é Beleza". Coleção Primeiros Passos, vol. 167, 3. ed. São Paulo, Brasiliense, 1991).

19 O Instituto Mário Alves (IMA) é um instituto voltado ao desenvolvimento de estudos e pesquisas políticas, econômicas e sociais. Tem como proposta central a criação de um espaço 


\section{VESTÍGIOS DE UMAAUSÊNCIA}

como a militante do Movimento Estudantil da época, Margareth Badejo. No Balneário Cassino, foram exibidos filmes ${ }^{20}$ que, depois de assistidos, foram discutidos.

Os cartazes de divulgação foram feitos com fotos dos integrantes do grupo, fazendo uma referência aos antigos cartazes que estampavam o rosto de supostos terroristas procurados. Estes cartazes eram distribuídos pela cidade e conclamavam os cidadãos a delatar, para o seu bem e de seus familiares, os indivíduos ali retratados. E solidariamente nos colocamos em seus lugares, tendo a certeza de que se tivéssemos vivido em tal período, também poderíamos ser tratados como terroristas. Em uma cidade relativamente pequena ${ }^{21}$, sabíamos que em alguns casos poderíamos ser reconhecidos. Este fato traria para o âmbito da pessoalidade e da familiaridade algo que, a princípio, estava tão distante e, provavelmente, não afetaria diretamente o público. Os cartazes foram distribuídos pelo Campus da Universidade, em ruas da cidade, paradas de ônibus e outros locais com grande afluência de pessoas.

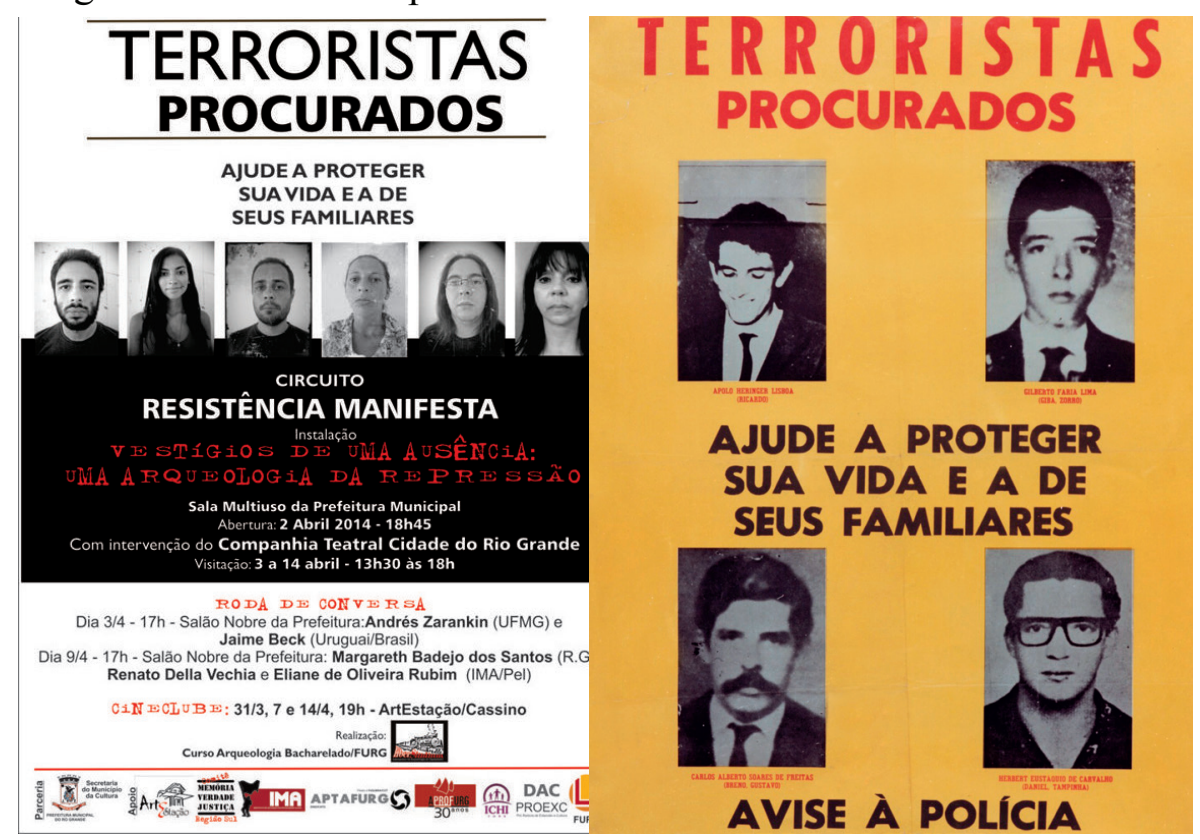

Fig. 1A: Na direita, cartaz de divulgação do evento realizado no recinto do DiretórioAcadêmico da Universidade Federal do Rio Grande. Imagem: Célia Maria Pereira. Fig. 1B: Na esquerda,cartaz da época da Ditadura. Fonte: http://folhetando.blogspot.com.br.

que promova a discussão, elaboração e a formação política, objetiva a participação de pessoas, instituições, movimentos sociais e entidades (governamentais e não governamentais). Fonte: http://www.imapelotas.blogspot.com.br/2009/09/o-ima.html.

20 Os filmes foram: Que bom te ver viva, direção de Lúcia Murat, que teve como debatedor Lizandro Mello; Batismo de Sangue, dirigido por Helvécio Rattom; e Zuzu Angel de Sérgio Rezende.

21 Conforme o Censo 2010, a população de Rio Grande - RS é composta por 94.983 homens e 102.245 mulheres, atingindo, naquele ano, quase 200.000 habitantes (http://www. cidades.ibge.gov.br). 


\section{A SAUDADE É ARRUMAR O QUARTO DO FILHO QUE JÁ MORREU}

A estrutura da instalação foi pensada detalhadamente para que o público fosse fortemente impactado com o lado perverso da repressão e depois fluísse para a materialidade, refletindo a ausência dos indivíduos brasileiros desaparecidos durante a ditadura. $\mathrm{O}$ intuito da proposta da instalação era criar ambientes em que as pessoas ficassem livres para interpretar o que quisessem sobre aquela arqueologia da repressão. Iríamos usar da cultura material para alcançar a sensibilidade dos sentidos e a percepção de cada pessoa que entrasse na instalação, possibilitando com que cada uma delas fizesse parte da instalação em si, criando o seu próprio discurso ali dentro.

Dividimos a instalação em cinco ambientes diferentes. O primeiro deles era a $E n$ trada, onde as pessoas eram recepcionadas pelo título da instalação e seu ícone, o pau de arara. Neste mesmo ambiente, selecionava-se um nome escrito em um pedaço de papel entre vários acondicionados em uma caixa preta.

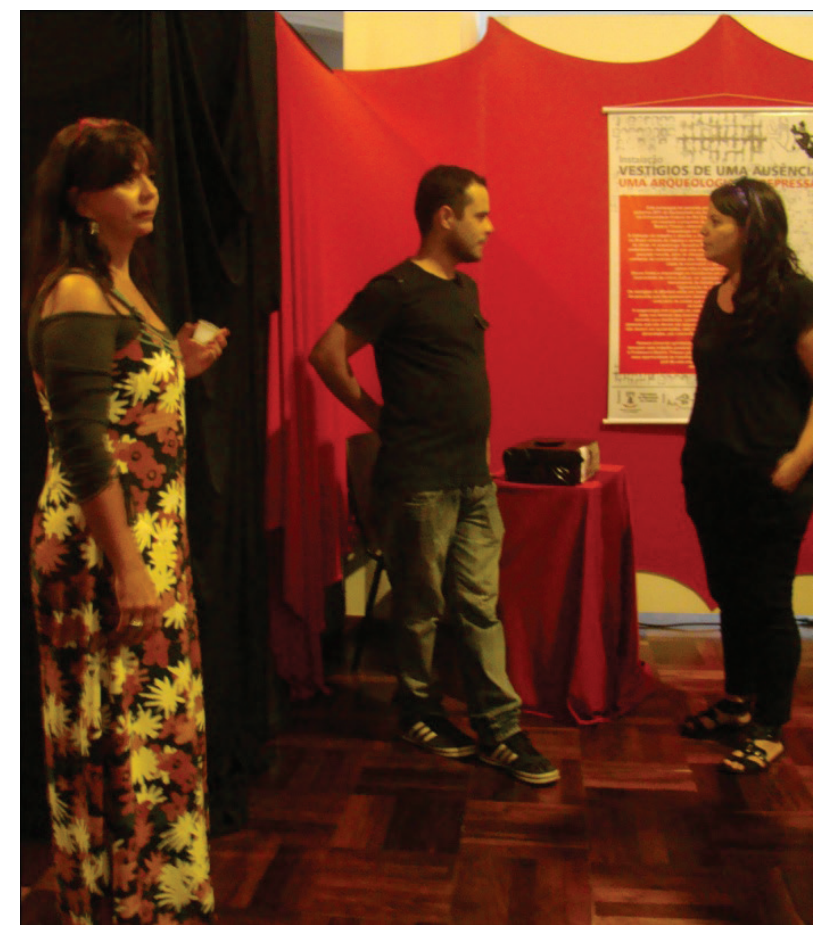

Fig. 2: Entrada da InstalaçãoVestígios de uma Ausência: uma Arqueologia da Repressão. Foto: Célia Maria Pereira, 2014.

O segundo ambiente era o Quarto Escuro. Este era, de fato, o primeiro ambiente em que a pessoa ficava só. Era uma pequena sala, completamente escura, sem luz e sem ventilação, onde o som de relatos de torturados, gritos e descrições de métodos de tortura se misturavam aos sons de discursos dos generais da ditadura - especialmente 


\section{VESTÍGIOS DE UMAAUSÊNCIA}

os que anunciavam as medidas de exceção - e a narração de jogos da copa do mundo de 1970. Os sons vinham de todos os lados através de caixas colocadas estrategicamente nos quatro cantos do quarto. Ao mesmo tempo, em uma parede, projetou-se continuamente um vídeo que apresentava um turbilhão de imagens desfocadas de pessoas sendo torturadas. Essas imagens eram interrompidas por fotografias dos mortos da ditadura. Como estas:

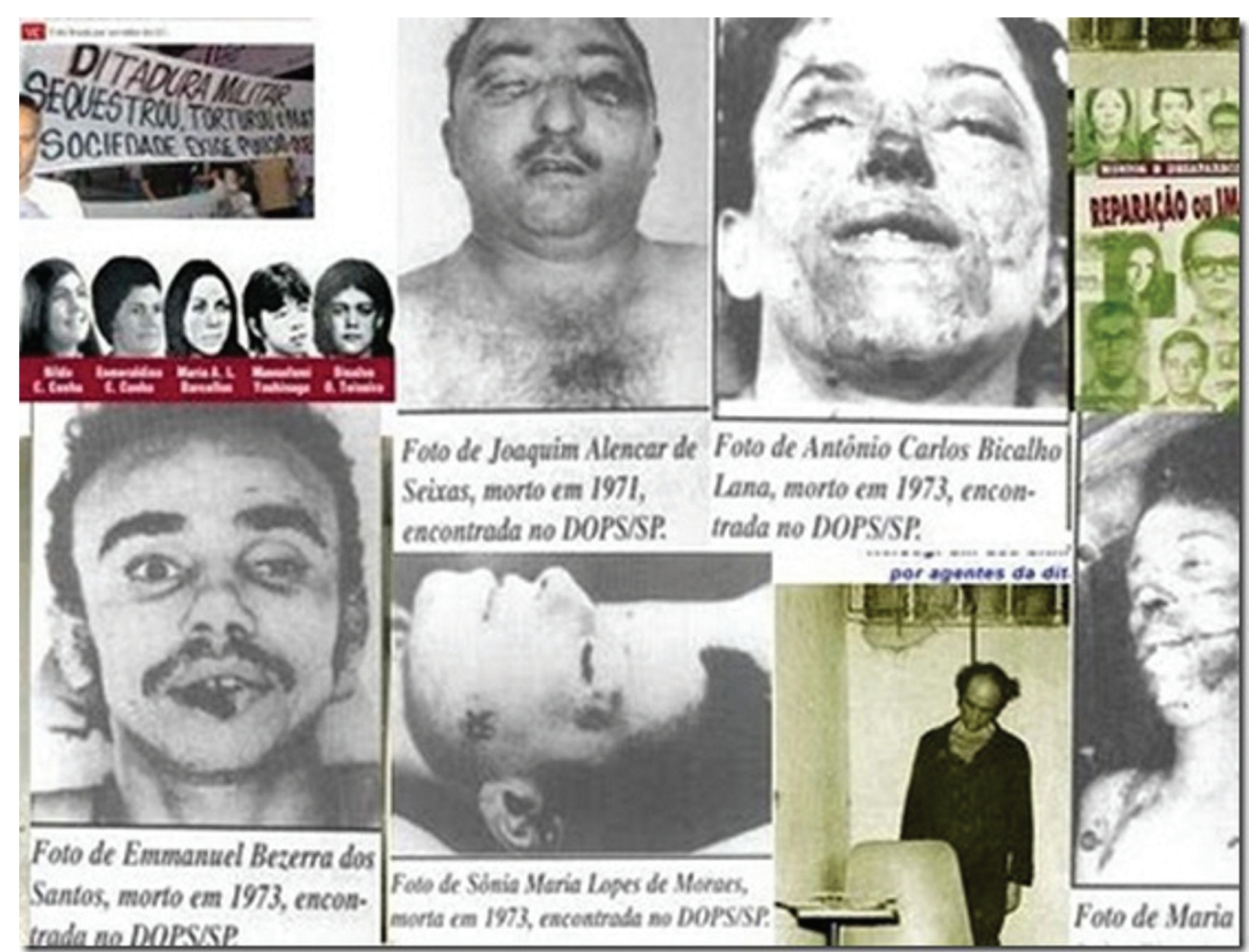

Fig. 3: Imagens projetadas no Quarto Escuro de torturados na ditadura. Fonte: http://zequinhabarreto. org.br/?p=7002

Ficava-se ali... Até quando fosse possível aguentar. Em pé. Naquele ambiente caótico, pavoroso, terrificante. Alguns ficavam segundos e voltavam, indo embora, abandonando a instalação. Outros seguiam adiante. Poucos toleravam ficar por muito tempo ali. Quando não era mais possível suportar, achava-se uma saída que, de fato, ficava escondida entre lonas pretas.

O terceiro ambiente, mais conhecido como a Sala dos Rostos, tinha uma luz tênue e, ao contrário do ambiente anterior, era todo branco, amplo e silencioso. E a única coisa que se via era o mural com o rosto, nome, idade, profissão e data de desaparecimento de sessenta e quatro brasileiros ${ }^{22}$ projetados na parede ao fundo. A pessoa identificaria

22 Fizemos a seleção dos sessenta e quatro desaparecidos políticos conforme os seguintes dados: nome completo, profissão, idade, imagem do rosto e data de desaparecimento. Tais da- 
ali o rosto daquele nome que tinha retirado na Entrada. Encontravam-se homens e mulheres, jovens e velhos, estudantes ou profissionais. Todos desaparecidos. A sensação era de um intenso vazio.

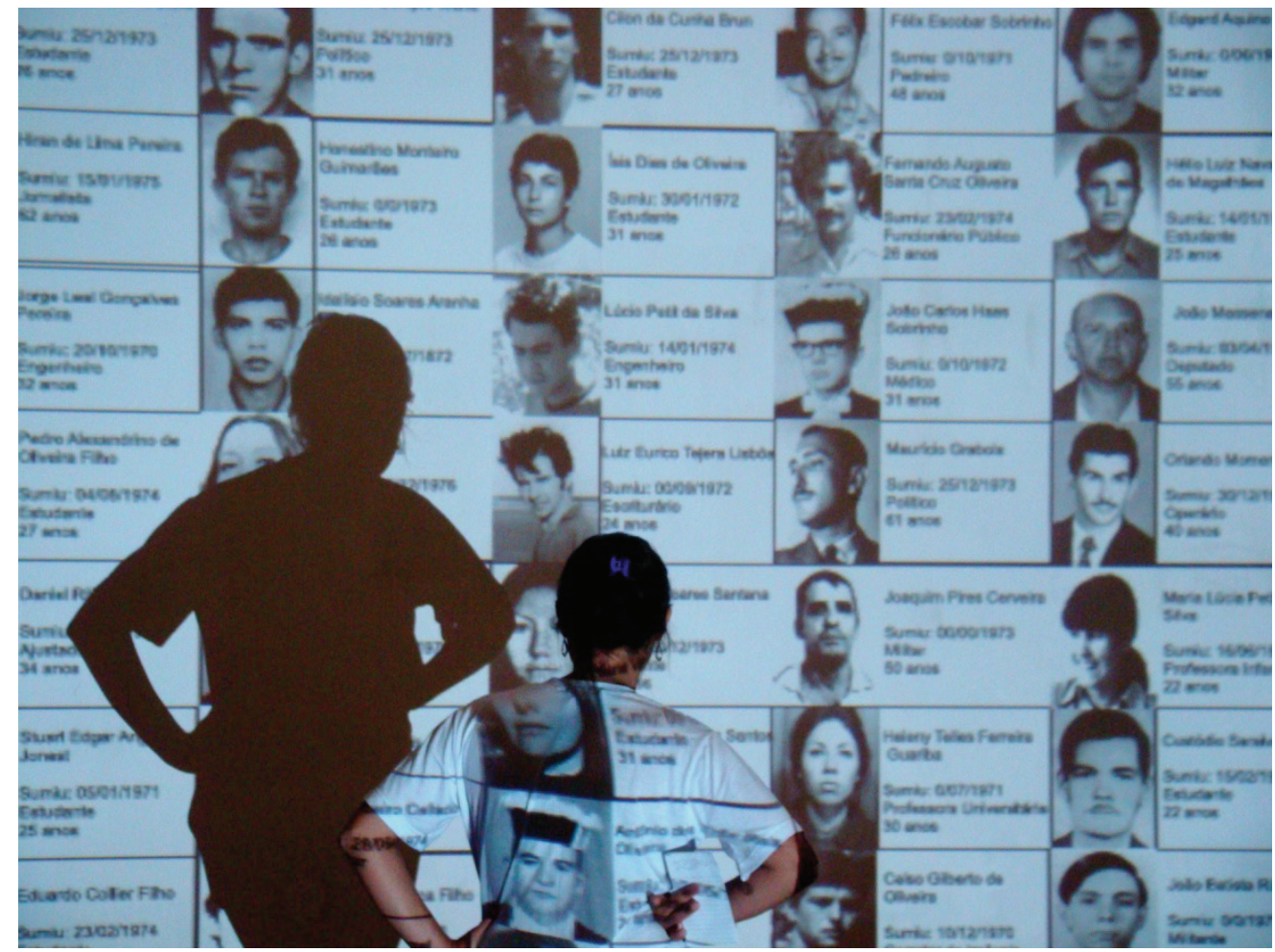

Fig. 4: Imagem projetada na Sala dos Rostos. Foto: Célia Maria Pereira, 2014.

O quarto ambiente era chamado Quarto da Ausência. Era justamente o que o nome diz ser, um quarto de um(a) jovem que estava estagnado no tempo. Era um quarto ambientado de acordo com o final da década de 1960 e começo da década de 1970, época em que houve mais denúncias de desaparecimentos e mortes de militantes. O quarto apresentava vários objetos e cheiros que refletiam a imagem de um(a) jovem militante e a sua ausência naquele lugar congelado no tempo.

Um quarto comum: os chinelos ao lado da cama, uma escrivaninha com uma máquina de escrever ainda com uma folha parcialmente escrita, livros de Karl Marx, um violão sobre a cama, uma figura de Che Guevara na parede, almofadas e discos no chão. Havia fotos também. Nessas fotos, sempre uma pessoa apagada. Uma sombra onde deveria estar uma criança entre os pais. Outra sombra, onde deveria estar um jovem entre

dos foram retirados do sítio http://www.desaparecidospoliticos.org.br, que é organizado pela Comissão Nacional da Verdade, entidade que age na luta contra a omissão e o esquecimento desses crimes cometidos na ditadura. Portanto, esses sessenta e quatro indivíduos fazem parte de um grupo muito maior de desaparecidos políticos no país. 


\section{VESTÍGIOS DE UMAAUSÊNCIA}

seus amigos. E assim por diante. Um quarto que ficou ali, sem que houvesse alguém para povoá-lo. O quarto vazio. O quarto da ausência. Ali, as pessoas se emocionavam.

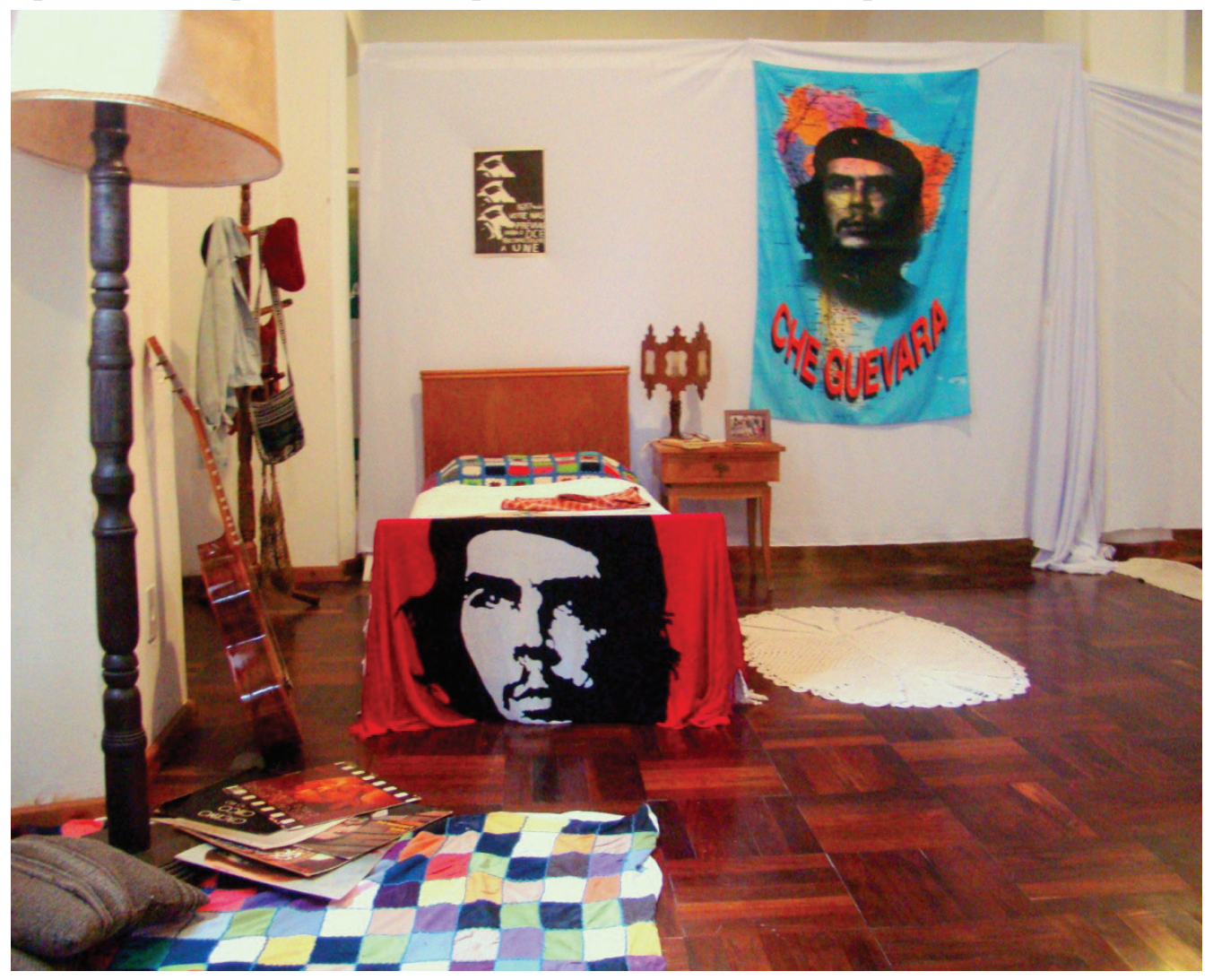

Fig. 5: Vista geral do Quarto da Ausência. Foto: Célia Maria Pereira, 2014.

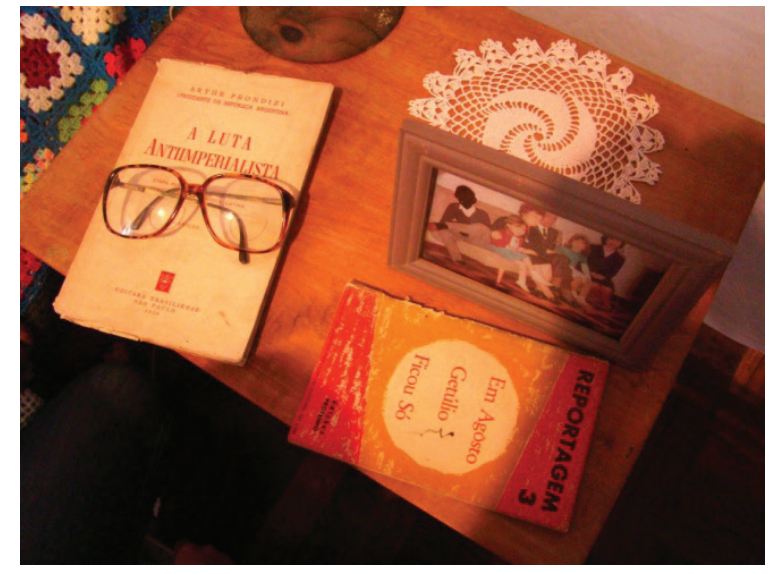

244 Revista de Arqueologia Pública, No. 10, pp. 232-250, Dezembro de 2014 

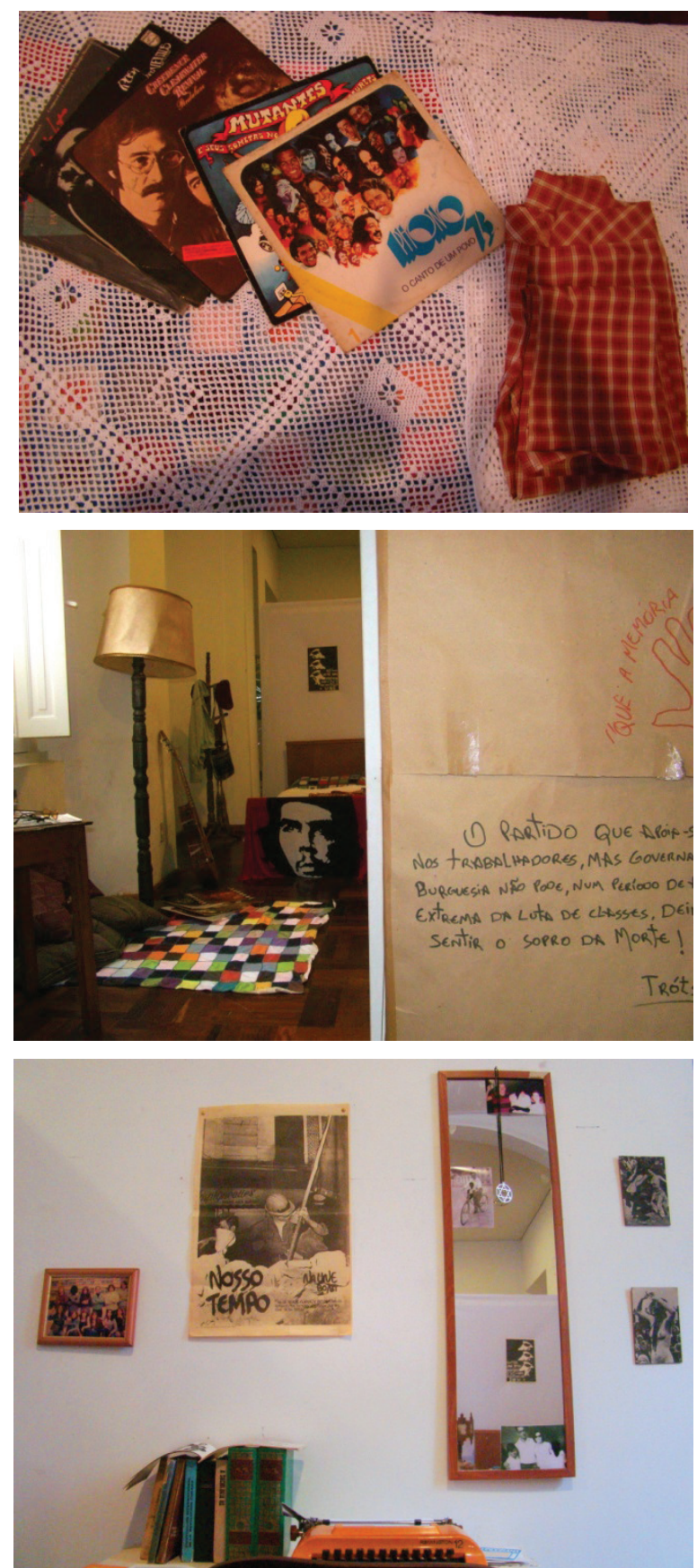

Figs. 6, 7, 8, 9: Aspectos do Quarto da Ausência. Foto: Célia Maria Pereira, 2014.

O quinto e último ambiente foi o Mural de Escritos, onde painéis expositores foram revestidos de papel pardo para que as pessoas, recém-saídas do Quarto da Ausência, também pudessem deixar seus vestígios na instalação. Este ambiente era bem claro e ali se ouvia canções que serviram de resistência e protesto naqueles anos. Cantores como Chico Buarque, Elis Regina, Geraldo Vandré e Milton Nascimento foram alguns dos artistas escolhidos para fazer o plano de fundo e manter o clima de envolvimento no 


\section{VESTÍGIOS DE UMAAUSÊNCIA}

momento de deixar seu depoimento ${ }^{23}$.

É importante esclarecer que ninguém foi obrigado a escrever no mural. Ao sair do Quarto da Ausência - por vezes emocionadas ou chocadas - as pessoas eram instruídas, se quisessem, a deixar no mural um vestígio seu: um sentimento, uma indignação. A sua parte no nosso trabalho.
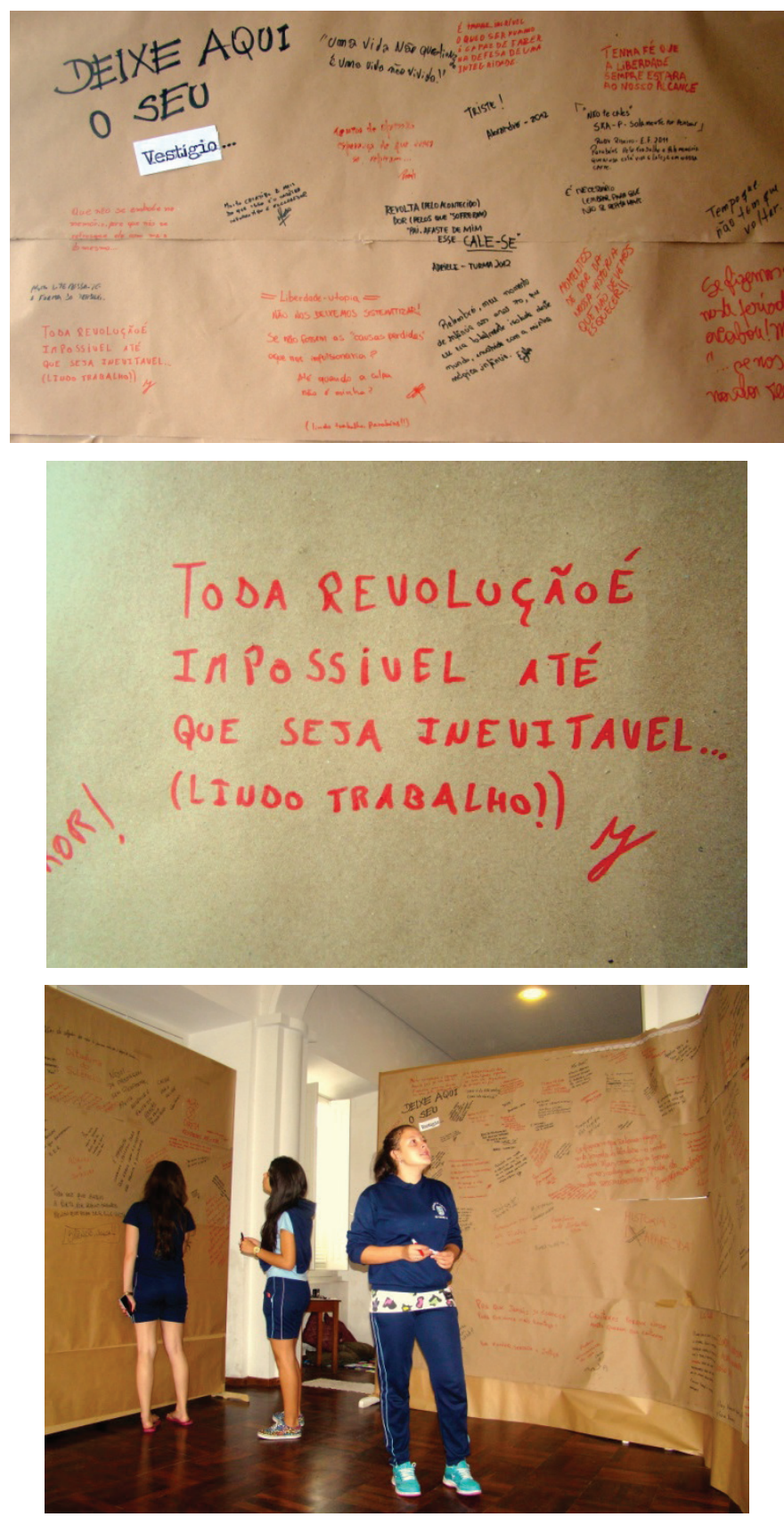

23 Os depoimentos no mural foram feitos espontânea e anonimamente.

246 | Revista de Arqueologia Pública, No. 10, pp. 232-250, Dezembro de 2014 


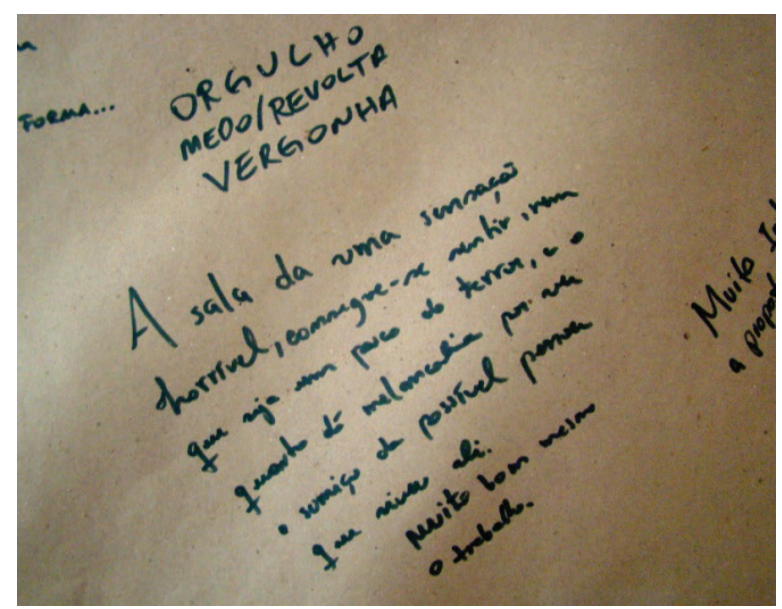

Fig. 10: Deixe aqui o seu vestígio... Fig. 11: Uma das frases no mural. Fig. 12: Visita de estudantes.

Fig. 13: Detalhe do Mural. Fotos: Célia Maria Pereira, 2014.

Acreditamos que o mural foi mais do que o retorno do público: foi uma recompensa. Foi então a nossa vez de nos emocionar e ter certeza de que o nosso objetivo foi cumprido: a cultura material por si só, as diversas coisas colocadas juntas no contexto certo expressam o que palavras não diriam. Conseguimos então demonstrar o poder que a arqueologia tem de, através da cultura material, despertar sentimentos, indignação e, principalmente, pertencimento e empatia.

Numa tarde que tinha tudo para ser igual a qualquer outra, as pessoas que se dispuseram a visitar a instalação saíram de lá com sentimentos diversos:

-"Nojo!"

-“Triste!"

-“Orgulho, Medo/Revolta, Vergonha!".

-“Agonia, Revolta, desespero, aperto no coração...”.

-"Esperança de que nunca se repita"

-"Momentos de dor...".

-“Relembrei minha infância nos anos 70...”.

-“Cenas que nos fazem refletir... Obrigada pelas sensações, por me tirar da zona de conforto!"

-"Afasta de mim esse cale-se!"

-“A sala dá uma sensação horrível, consegue-se sentir, nem que seja um pouco de terror, e o quanto dá melancolia por ver o sumiço da possível pessoa que viveu ali."

-“Assim como na época de ditadura me senti desorientado e confuso com as narrativas de futebol de tal maneira que fiquei um pouco alienado com as imagens que passaram na minha frente. O espetáculo do futebol usado para alienar as pessoas".

Nós, envolvidos no trabalho, nos dividimos em pequenos grupos de dois ou três para podermos auxiliar o público em todos os horários que a instalação ficou aberta. 


\section{VESTÍGIOS DE UMAAUSÊNCIA}

Portanto, de maneira geral, todos nós tivemos um contato muito direto com o público, possibilitando avaliar diariamente como a proposta impactava os visitantes.

Apesar da emoção geral do público, era impossível pensar que não haveria manifestações a favor do regime militar. Um aluno pertencente a uma turma de ensino médio de certa escola pública da cidade escreveu: "Não há futuro para o país sem a ditadura". A professora levou as respostas dos alunos como um tema a ser discutido em sala de aula, chamando atenção para as diversas versões que se contam sobre o período. Esta foi a única manifestação favorável à ditadura que recebemos. Em contrapartida, muitas pessoas escreveram chamados de revolução:

-’Toda revolução é impossível até que seja inevitável".

-"Não podemos desistir, não podemos por eles, por nós pelo povo!"”.

-"Hay hombres que luchan un dia y son Buenos/Hay otros que luchan un año y son mejores/ Hay quienes luchan muchos años y son muy Buenos/ Pero hay los que luchan toda la vida/ Esos son inprescindibles" (citando Bertold Brecht).

-"Liberdade-Utopia".

-“Não nos devemos Sistematizar! Se não fossem as 'causas perdidas' o que nos impulsionaria? Até quando a culpa não é minha"?

\section{A SAUDADE É O PIOR CASTIGO E EU NÃO QUERO LEVAR COMIGO A MORTALHA DO AMOR}

Entendendo a Arqueologia como uma disciplina dotada de grande responsabilidade social e política, a instalação possibilitou ao público relacionar experiências de um passado sombrio com o presente. Em meio à ebulição popular vivida nos últimos meses, percebeu-seque ainda vivemos com marcas daquele tempo. A força desproporcional, a brutalidade policial que, a serviço do poder, parece fazer uma limpeza nas ruas, permitiu aos visitantes uma reflexão do panorama atual do país. A questão da desmilitarização da polícia apareceu em falas. Através do mural feito de papel pardo, a comunidade pode interagir e deixar o seu testemunho. Quisemos ouvir o que cada um tinha a dizer. Quisemos que cada um deixasse seu vestígio.

A instalação trouxe ao público talvez uma redescoberta, uma nova visão sobre o nosso trabalho, que rotineiramente é tratado como um mero entretenimento, dotado de aventuras fantásticas com segredos preciosos, e que se atém apenas ao antigo. Ou, como quando uma das integrantes do grupo foi questionada: "Por que isso é arqueologia e não história?". Foi um deleite finalmente poder responder: - "É arqueologia, pois trazemos as coisas à tona". A materialidade traz a vida que os documentos escritos usurpam. Não que a história não tenha o poder de emocionar com os textos, mas é absolutamente dife- 
rente ler sobre os fornos utilizados nos campos de concentração nazistas e deparar-se com o sapatinho de uma criança incinerada dentro de um, como frizou Lizandro $\mathrm{Mello}^{24}$ em sua fala após a exibição do filme Que bom te ver Viva.

Conseguimos mostrar que é possível ir além, e proporcionar momentos mais incríveis do que uma personagem sendo perseguida por uma bola gigantesca em uma de suas aventuras ${ }^{25}$. Talvez sim, talvez tenhamos um toque de magia, talvez nossa magia seja a possibilidade de tocar as pessoas e proporcionar essa reflexão ao escancarar o sujo, o feio, o que revolta, opondo-se assim a qualquer mecanismo de higienização do passado.

\section{AGRADECIMENTOS}

Agradecemos a todos os alunos da disciplina de Arqueologia do Capitalismo III, do curso de Bacharelado em Arqueologia da Universidade Federal do Rio Grande - FURG -, que se envolveram neste projeto. Agradecemos ainda, ao Liber Studium, Laboratório de Arqueologia do Capitalismo da FURG, à Direção de Arte e Cultura da Pró-Reitoria de Extensão desta Universidade, à Secretaria de Município da Cultura do Rio Grande, à Associação dos Professores da FURG (APROFURG), ao Sindicato do Pessoal Técnico-Administrativo da FURG (APTFURG), ao DCE da FURG, ao Ponto de Cultura ArtEstação e ao Instituto Mario Alvez.

Agradecemos, sobretudo, aos que lutaram para que hoje pudéssemos estar aqui.

\section{REFERÊNCIAS BIBLIOGRÁFICAS}

BAUDRILLARD, Jean. Simulacros e Simulação. Lisboa, Relógio d'Água Editores Ltda, 1991.

CONNERTON, Paul. How Modernity Forgets. Cambridge, Cambridge University Press, 2009.

24 Bacharel em Direito (FURG, 2007), Advogado (OAB/RS 73.076), Bacharel em História / Patrimônio Cultural (FURG, 2013). Atua nas áreas de Direitos Humanos, Direito Criminal, Patrimônio Cultural, Ditaduras de Segurança Nacional na América Latina no período Pós-II Guerra, Direito e Justiça Social. Foi convidado para participar da roda de discussão sobre o filme "Que bom te ver viva" de Lúcia Murat, no Circuito Resistência Manifesta.

25 Fazemos referência aqui ao filme: Indiana Jones e os Caçadores da Arca Perdida, de Steven Spilberg. 


\section{VESTÍGIOS DE UMAAUSÊNCIA}

LITTLE, Barbara J.; SHACKEL, Paul A. Archaeology, Heritage, and Civic Engagement: Working Toward the Public Good. WalnutCreek, Left Coast Press, 2014.

GLOSSÁRIO + Regras do Jogo. Material Educativo da 29a Bienal de São Paulo. São Paulo, Bienal, 2010.

McGUIRE, Randall H. Archceology as Political Action. Berkeley and Los Angeles, University of California Press, 2008.

MENESES, Ulpiano B. A. "História, Cativa Da Memória? Para um Mapeamento da Memória no Campo das Ciências Social". Revista do Instituto de Estudos Brasileiros, São Paulo, no 34, p. 11, 1992.

POTTER Jr., Parker B. Public Archaeology in Annapolis: A Critical Approach to History in Maryland's Ancient City. Washington, Smithsonian Institution Press, 1994.

RUIBAL, Alfredo G. "Time to destroy. An archaeology of supermodernity". Current Anthropology, $n^{\circ}$ 49(2), p. 247-279, 2008.

SILVA, Veruska A. S. da. "Memória e Afetividade: A Importância das Emoções nas Trajetórias Sociais". OPSIS Dossiê História e Sensibilidade Universidade Federal de Goiás/Campus Catalão, v. 8, n. 11, p. 59-76, 2008. 